\title{
INVESTIGATION OF THE SPREAD OF BRUCELLOSIS AMONG HUMAN AND ANIMAL POPULATIONS IN SOUTHEASTERN BULGARIA, 2007
}

\author{
V Tzaneva ()', S Ivanova², M Georgieva ${ }^{2}$, E Tasheva² \\ 1. University Hospital, Stara Zagora, Bulgaria \\ 2. Regional Inspectorate for Public Health Protection and Control, Haskovo, Bulgaria
}

Three human cases of brucellosis were reported in summer 2007 in the region of Haskovo in southeastern Bulgaria. Subsequently, the regional veterinary and public health authorities carried out investigations to determine the spread of infection in domestic animals and in the human population. As a result, over 90,000 animals were tested, and 410 were found infected with brucellosis. The screening of 561 people believed to have been at risk of infection yielded 47 positive results. The majority of these persons had direct contact with domestic animals or had consumed unpasteurised dairy products. The investigations revealed evidence of disease among animals in the region and a considerable risk to humans, thus emphasising the need for effective prevention and control programmes.

\section{Introduction}

Brucellosis, also called undulant fever or Malta fever, is a zoonotic infection caused by Gram-negative bacteria of the genus Brucella. Brucella melitensis affects predominantly small ruminants, such as goats and sheep, $B$. abortus is found mainly in cattle and $B$. suis in pigs, whereas $B$. canis occurring in dogs is the least common. Transmission to humans may take place by direct contact with affected animals or their post-partum/post-abortion secretions, by ingestion of contaminated, unpasteurised food (mainly dairy products), and by inhalation of infected aerosols. The potential to infect humans and animals through aerosol exposition has raised the possibility of deliberate use of Brucella spp. as a biological weapon [1].

The mean incubation period in humans is $2-10$ weeks, but could range from several days up to six months. The symptoms include intermittent fever, chills, asthenia, fatigue, weakness, malaise, arthralgias, low back pain, headache, anorexia. Chronic untreated brucellosis can lead to osteoarticular or, less commonly, genitourinary complications, in some cases even death $[2,3]$.

Globally, brucellosis remains a serious problem, with more than 500,000 cases per year worldwide. In Europe, brucellosis affects mainly the Mediterranean countries, but the epidemiology of this infection has been changing over the past decade due to various sanitary, socioeconomic, and political factors, and to international travel [4]. In 2006, a total of 1,313 human cases, of which 955 were confirmed, were reported in the European Union (EU) countries, representing a notification rate of 0.20 per 100,000 . Twelve countries reported zero cases. The highest notification rates per 100,000 were reported by Greece (1.1), Italy (0.78), Portugal (0.72) and Spain (0.3) [5].

In Bulgaria, since 1903, only sporadic cases had been reported in humans. However, during the last few years, the numbers increased; 37 cases were reported in 2005 and 11 in 2006 $[6,7]$. In 2007, in the course of the investigations described in this paper, 50 cases were identified in the province of Haskovo in southeastern Bulgaria (Figure 1), which brought the total number of cases registered in the country to 57 .

The investigations reported here were undertaken after three cases with clinical symptoms and laboratory confirmation of brucellosis had been detected in the town of Harmanli (two cases) and a nearby village of Valche pole (one case) in the Haskovo region. The objectives were to determine the spread of disease in domestic animals, conduct active case-finding in the human population potentially exposed to infection, identify risk factors and provide recommendations for appropriate control and response measures.

\section{Methods}

\section{Case investigation}

Brucellosis has been a notifiable disease in Bulgaria since 1903. The current case definition is based on the EU case definitions [8] as stated in the 2005 national legislation on registration, notification and reporting of communicable diseases [9].

Cases were interviewed using a standard questionnaire collecting information on the epidemiology and clinical presentation of brucellosis: contact with animals and consumption of unpasteurized dairy products, and possible symptoms, such as malaise, fever, chills, sweats, headache, neck pain, low back pain, joint pain, muscle pain, occasionally diarrhoea, constipation, anorexia, weight loss, and abdominal pain.

\section{Epizootiological study}

In the region of residence of the first three reported cases of brucellosis an epizootiological investigation was carried out by the Haskovo regional inspectorate for public health protection and 
control (RIOKOZ) and the regional veterinary services (RVMS). Serologic screening of domestic animals - goats, sheep, cattle, horses and donkeys - was carried out in 10 localities: Valche pole village in Ljubimetch municipality, Harmanli town and five villages in Harmanli municipality, Mramor village and Ustrem village in Topolovgrad municipality, and Levka village in Svilengrad municipality. Sera samples were obtained from a total of 90,345 animals. The first animals were screened following the notification of the first case from Valche pole in August 2007. Then the area was broadened to include places inhabited by the two subsequent cases reported in September and the neighbouring localities and the investigations continued with periodic screening performed every three months.

The serologic tests conducted were Rose Bengal and complement binding reaction. The positive samples were sent for confirmation to the reference laboratory for brucellosis in the National Diagnostic Scientific Veterinarian Medical Institute where Rose Bengal, complement binding reaction and ELISA were performed.

\section{Study in the human population}

The total population living in the area is 22,335 inhabitants.

We estimated the size of the population exposed to risk of infection, by identifying those who may have had contact with infected animals or consumed products originating from these animals (families living at the farms where cases in animals were detected and their visitors). From the veterinarians who performed the epizootiological study we received information on owners of animals which tested positive for brucellosis. On the basis of this data, a list of farmers whose animals had tested positively for brucellosis was established. To this list, we added their families and friends and relatives who had visited the farm and therefore may have had contact with the infected animals.

In total 561 persons were identified for serologic screening and 581 sera were tested. The serologic investigation was carried out in the laboratory for hazardous infections in the National Center of Infectious and Parasitic Diseases (NCIPD) and in the reference laboratory for brucellosis in the National Diagnostic Scientific Veterinarian Medical Institute.

Three single serologic tests were performed for each person. The samples were accompanied with information about the name, age and place of residence of the contact person. Rose Bengal and Wright tests were carried out for 329 people and Brucellacapt, Rose Bengal and Wright tests were performed for 232 persons.
We also performed a survey using a standard questionnaire collecting information about possible contact with animals and consumption of unpasteurised food products as well as clinical signs and symptoms indicating brucellosis. All 561 persons were surveyed.

\section{Results}

\section{Case investigation}

In August and September 2007 the regional inspectorate for public health protection and control (RIOKOZ) in Haskovo was notified about three cases of brucellosis in residents of the region - one from village Valche pole and two from the town Harmanli. In all three cases the diagnosis of brucellosis was laboratory-confirmed according to the case definition $[7,8]$. The disease developed in two women and one man. The data from the extended clinicalepidemiological investigation are as follows:

\section{Case 1}

In the end of July 2007, a 62-year-old woman was admitted to hospital in Plovdiv with symptoms of fever, low back pain, urine frequency and dysuria, muscle pains and shivering. The initial diagnosis was pyelonephritis but further tests in August yielded positive result for brucellosis by ELISA. The patient history revealed that the woman lived in the village Valche pole during the spring and summer periods. Her sister's family breeded domestic animals and the patient consumed milk products originating from these animals without preliminary heat treatment. In the course of subsequent epizootiological investigations, four animals from this farm - sheep and goats - tested positive for brucellosis.

\section{Case 2}

A man, aged 62 years, presented with symptoms of fever, chills and low back pain in the end of May 2007. The initial diagnosis was pyelonephritis and an outpatient treatment was initiated. In July the patient was again with fever, chills and joint pain. A maculo-papulous rash appeared and he was admitted to the infectious diseases ward in the hospital in Haskovo with diagnosis of Marseilles fever (boutonneuse fever), but the disease was not confirmed serologically. He remained febrile and developed inflammation of the testis and epididymis. On the basis of the patient history - breeding domestic animals and consumption of milk products without the necessary heat treatment - a suspicion of brucellosis was raised and a serological test performed. The results obtained in mid-September were positive.

Later screening of his animals also yielded positive results.

T A B L E

Results of active case-finding among the population at risk of brucellosis infection in Haskovo province in southeastern Bulgaria, 2007

\begin{tabular}{|l|c|c|c|c|}
\hline \multirow{2}{*}{ Place of residence } & Study & Number of people who tested & \multicolumn{2}{|c|}{ Those who tested positive for brucellosis } \\
\cline { 4 - 5 } & population & $\begin{array}{c}\text { Cositive for brucellosis } \\
\text { Consumption of milk products } \\
\text { without heat treatment }\end{array}$ & $\begin{array}{c}\text { Contact with animals } \\
\text { positive for brucellosis }\end{array}$ \\
\hline Ljubimetch municipality: Valche pole village & 158 & 5 & 4 & 29 \\
\hline Harmanli municipality & 243 & 29 & 13 & 20 \\
\hline Topolovgrad municipality: Ustrem and Mramor village & 150 & 13 & - & 11 \\
\hline Svilengrad municipality: Levka village & 10 & - & 46 & - \\
\hline Total & 561 & 47 & & 35 \\
\hline
\end{tabular}


Case 3

A 74-year-old woman, resident of Harmanli, fell ill in September 2007 with fever, gastrointestinal symptoms and loss of weight. In the course of the diagnostic process a positive result for brucellosis was obtained. The patient kept domestic animals - her goats had given birth to dead kids in December 2006 and January 2007. She had consumed milk products without the necessary heat treatment.

\section{Epizootiological investigation}

In total, 90,345 animals - goats, sheep, cattle, horses and donkeys - from 10 localities in the region were tested for brucellosis. Of these, 403 small ruminants (sheep and goats) and seven cattle were found infected. During the time of the screening none of the animals had symptoms of the disease, but some of the owners reported miscarriages and stillbirths in their farm animals during the winter and spring of 2007.

\section{F I G U R E}

Map of Haskovo province in southeastern Bulgaria where human and animal cases of brucellosis were detected in 2007

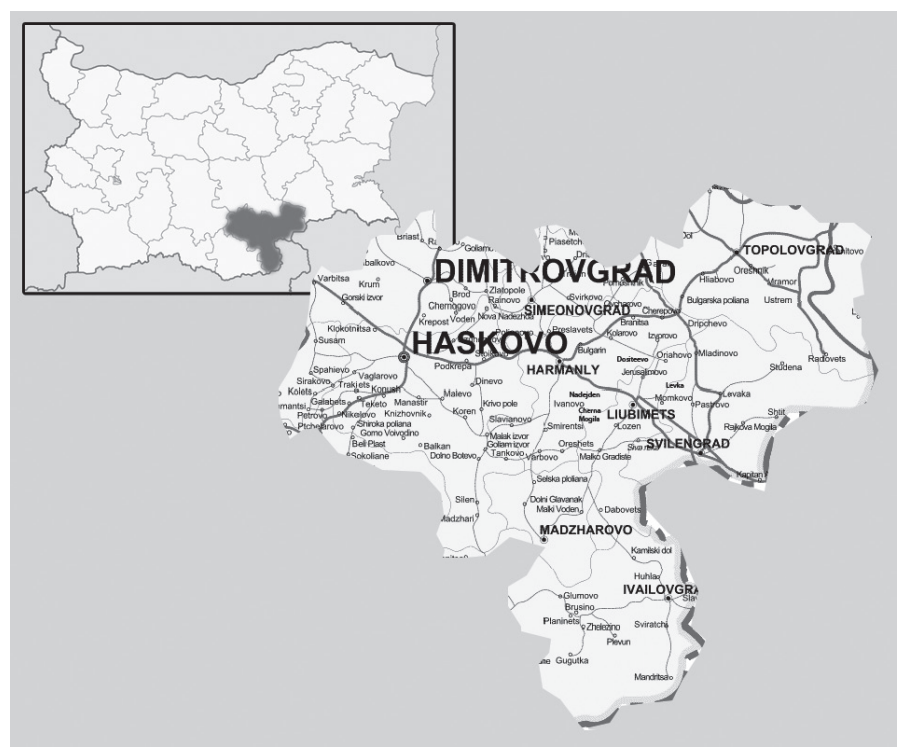

F I G U R E 2

Age distribution of human cases of brucellosis in the province of Haskovo, Bulgaria, $2007(n=50)$

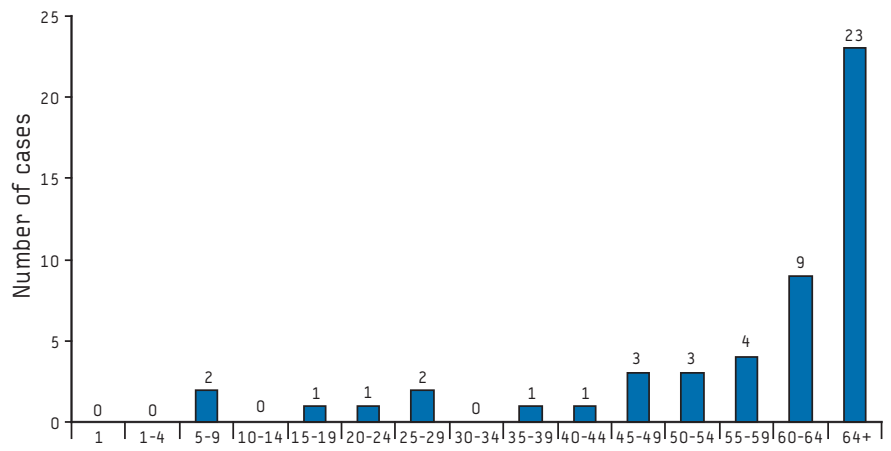

Age group (years)
As a result, 83 small farms were identified where animals with positive serology for brucellosis had been detected - 16 in Valche pole village (Ljubimetch municipality), 28 in the town of Harmanli, 38 in Mramor village (Toplovgrad municipality) and one in Levka village (Svilengrad municipality). Sporadic cases of infected animals were also detected in the villages Dositeevo, Dripchevo, Ivanovo, Cherna mogila and Nadejden from municipality Harmanli and Ustrem village from municipality Topolovgrad, where individual, small stock breeding farms exist.

\section{Study in the human population}

Of the 561 people screened for brucellosis, 47 tested positive. Five of these were residents of village Valche pole, 29 of the town Harmanli and 13 of village Mramor.

All 561 individuals were also interviewed. The survey confirmed that those infected had contact with infected animals or consumed unpasteurised milk products.

The results of these investigations are shown in the Table.

The results of the serological screening indicate that as an outcome of the epizootic process in the region the infection has spread to people: besides the three index cases with manifestation of symptoms, 47 persons with positive serology but without clinical signs and symptoms of the disease were identified.

The majority of these people had contact with infected animals and/or consumed unpasteurised milk products.

Among 158 people tested in village Valche pole in municipality Ljubimetch, five had positive serology. For four of these there was evidence that they had domestic animals in their individual farms that had tested positive for brucellosis and had consumed milk products without the adequate heat treatment. In municipality Harmanli, of the 243 investigated people 29 had positive serology. Of these all reported ingestion of milk products without the necessary heat treatment and 20 had animals that had tested positive. In Topolovgrad municipality, Ustrem and Mramor villages, of the 150 people tested, 13 had positive serology.

The majority of people who tested positive for brucellosis were over the age of 45 years and the largest age group was that of 64 years and older (Figure 2). The small number of cases among children could be explained by the fact that they more rarely than adults have contact with the animals. The proportion of men was $52 \%$ (Figure 3).

The majority of persons who tested positive for brucellosis had contact with animals via their occupation, either in individual farms as farmers or herdsmen, or as veterinarians (Figure 4).

\section{Discussion and conclusion}

The occurrence of brucellosis in humans is directly linked to the epizootic of animal brucellosis. The sources of infection are domestic animals and known risk factors for the development of the disease are direct contact with animals and consuming of unpasteurized milk and related dairy products $[10,11]$. The results of the joint investigations in the animal and human population reported here indicated that the spread of brucellosis in the region of Haskovo was notable and that the consumption of unpasteurised dairy products was a widespread common practice among the local population.

The testing of domestic animals followed by the screening of people who may have been at risk of infection proved to be a timely 
and adequate response to the detection of the first three human cases in the region, and the collaboration between the veterinary and public health authorities was very good.

Further measures included providing organisational and methodological support to all general practitioners in the region to raise awareness of brucellosis and ensure quick diagnosis and adequate treatment of infected patients. Information on the symptoms of brucellosis and ways of preventing infection was also given to the general public in printed booklets and online material published on the RIOKOZ website.

Brucellosis is a rare disease and physicians may not be aware of the initial clinical symptoms and of the diagnostic procedures necessary for the verification of the disease. Clinical symptoms

\section{F I G U R E 3}

Sex distribution of human cases of brucellosis in the province of Haskovo, Bulgaria, $2007(n=50)$

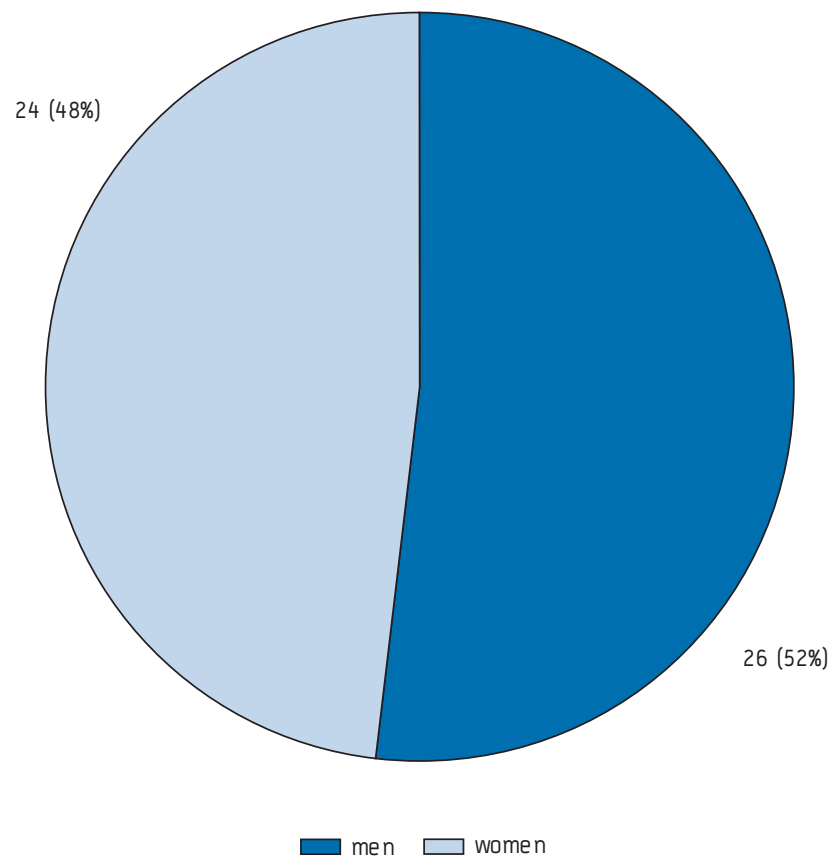

\section{F I G U R E 4}

Occupation reported by human cases of brucellosis in the province of Haskovo, Bulgaria, $2007(n=50)$

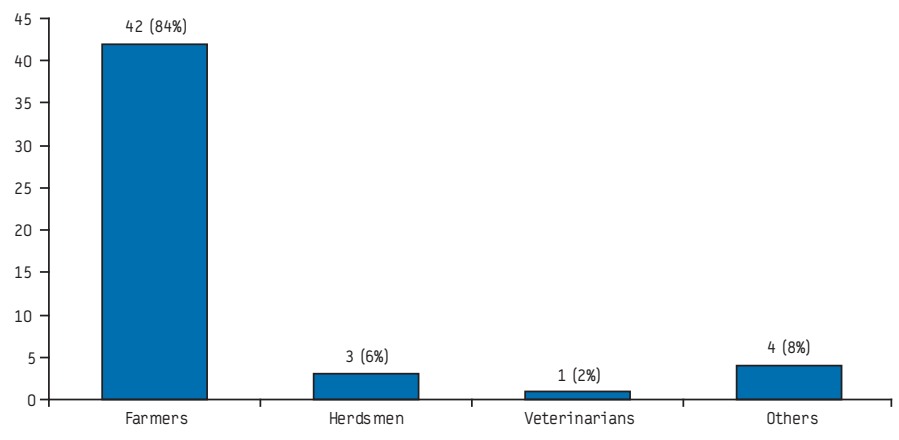

are not specific and patients may consult different specialists, which results in diagnostic delay. Treatment is difficult because of the intracellular nature of the infection and possibility for chronification. The therapeutic strategies are characterised by long duration and high cost of treatment $[12,13]$.

The events described in this paper emphasize the importance to develop a national programme and response protocol for prevention of brucellosis, and to improve the laboratory diagnostics. It is necessary to define in what intervals the serologic tests of the affected patient should be performed to document the response to therapy and when and who should be screened among the contacts. We also believe that general practitioners should work closely with specialists in infectious diseases in treatment and follow-up of patients with brucellosis.

The results of our epidemiological investigations indicate that control and eradication programmes among animals and proper food safety should be regarded as priority measures in prevention of brucellosis. This is crucial especially considering that there is no human vaccine available.

As a result of the events described here the veterinary authorities have continued the periodic screening of animals performed every three months in the region affected. A special programme regulates the preventive and control measures undertaken in case of brucellosis detected in animals.

Regarding human cases, a questionnaire for patients with brucellosis has been developed at the national level. Training courses have been offered to general practitioners and infectious diseases specialists on etiology, diagnosis and epidemiology of brucellosis.

In 2008, one case of brucellosis with clinical presentation of the disease and 10 asymptomatic cases were notified in Bulgaria.

\section{References}

1. Hoover D, Friedlander A. Brucellosis. In: Zajtchuk R, editor. Textbook of Military Medicine: Medical Aspects of Chemical and Biological Warfare. Washington, DC: US Department of the Army, Surgeon General, and the Borden Institute; 1997. p. $513-21$.

2. Corbel MJ. Brucellosis: an overview. Emerg Infect Dis. 1997;3(2):213-21.

3. Young EJ. An overview of human brucellosis. Clin Infect Dis. 1995;21(2):283-9.

4. Pappas G, Papadimitriou P, Akritidis N, Christou L, Tsianos EV. The new global map of human brucellosis. Lancet Infect Dis. 2006;6(2):91-9.

5. European Centre for Disease Prevention and Control. Annual Epidemiological Report on Communicable Diseases in Europe 2008. Report on the status of communicable diseases in the EU and EEA/EFTA countries. Available from: http://www.ecdc.europa.eu/en/Publications/AER_report.aspx

6. Tiholova M, Gotseva A, Baev M, Tchenkova M. Brucellosis - a reemerging disease in the country [in Bulgarian]. Infectology. 2006;43(2):44-7.

7. Tiholova M, Gotseva A, Baev M, Tchenkova M. Clinical investigation of first Brucellosis cases during an outbreak in Bulgaria [in Bulgarian]. Infectology. 2006;43(1):35-6.

8. Commission Decision of 28 April 2008 amending Decision 2002/253/EC laying down case definitions for reporting communicable diseases to the Community network under Decision No 2119/98/EC of the European Parliament and of the Council (notified under document number C(2008) 1589) (Text with EEA relevance). 2008/426/EC. Official Journal L 159, 18/06/2008 P. 0046 - 0090. Available from: http://eur-lex.europa.eu/LexUriServ/LexUriServ.do?uri=0J:L:2 008:159:0046:01:EN:HTML

9. Regulation on the procedure for registration, notification and reporting of communicable diseases [in Bulgarian]. Regulation nr 21, 18 July 2005. State Gazette, nr 62, 29 July 2005. 
10. Mishal J, Ben-Israel N, Levin Y, Sherf S, Jafari J, Embon E, Sherer Y. Brucellosis outbreak: analysis of risk factors and serologic screening. Int J Mol Med. 1999;4(6):655-8.

11. Vorou R, Gkolfinopoulou K, Dougas G, Mellou K, Pierroutsakos I, Papadimitriou T. Local brucellosis outbreak on Thassos, Greece: a preliminary report. Euro Surveill. 2008;13(25):pii=18910. Available from: http://www.eurosurveillance. org/ViewArticle.aspx?ArticleId $=18910$

12. Akova M, Uzun O, Akalin HE, Hayran M, Unal S, Gür D. Quinolones in treatment of human brucellosis: comparative trial of ofloxacin-rifampin versus doxycycline-rifampin. Antimicrob Agents Chemother. 1993;37(9):1831-4.

13. Ersoy Y, Sonmez E, Tevfik MR, But AD. Comparison of three different combination therapies in the treatment of human brucellosis. Trop Doct. 2005;35(4):210-2.

This article was published on 30 April 2009.

Citation style for this article: Tzaneva V, Ivanova S, Georgieva M, Tasheva E. Investigation of the spread of brucellosis among human and animal populations in southeastern Bulgaria, 2007. Euro Surveill. 2009;14(17):pii=19187. Available online: http://www. eurosurveillance.org/ViewArticle.aspx?ArticleId=19187 